\title{
PR-2
}

\section{A REVIEW ON MAGNETRON SPUTTER COATINGS}

\author{
Chintada. Vinodbabu, ${ }^{1 *}$ G. Thirumala Rao, ${ }^{2}$ N. Bakthavatchala Reddy, ${ }^{3}$ \\ Grigory V Zyryanov ${ }^{3,4}$ \\ ${ }^{1}$ Department of Mechanical Engineering, GMR Institute of Technology, \\ GMR Nagar, Rajam-532 127, A.P., India. \\ ${ }^{2}$ Physics Division, Department of Basic Science \& Humanities, \\ GMR Institute of Technology, GMR Nagar, Rajam-532 127, A.P., India. \\ ${ }^{3}$ Ural Federal University, Chemical Engineering Institute Yekaterinburg, \\ 620002, Russian Fedaration. \\ ${ }^{4}$ I. Ya. Postovskiy Institute of Organic Synthesis, \\ Ural Division of the Russian Academy of Sciences, 22 S. Kovalevskoy St., \\ 620219 Yekaterinburg, Russian Federation. \\ *Corresponding author e-mail: vinodbabu.chintada@gmail.com
}

\begin{abstract}
To modify the metal/non-metal surface properties like hardness, wear and corrosion resistance, surface coating technology is the easiest and inexpensive method. Out of various surface coating methods, sputter coating technique is a one of the prominent method to improve the surface properties. Sputter coating techniques are widely used in aerospace, automobile, solar panels and various engineering fields to improve the surface properties. Present study focused on various materials used in the sputter coating techniques to develop thin films on various components. Influence of coating materials on hardness, wear and corrosion resistance of the various materials like steels, magnesium and their alloys are also explained in detailed in this review.
\end{abstract}

